\title{
Anti-tumor characteristics of radiation-induced tumor-infiltrating neutrophils
}

\author{
Tsuguhide Takeshima*, Ellen Vitetta, Raquibul Hannan \\ From Society for Immunotherapy of Cancer 29th Annual Meeting \\ National Harbor, MD, USA. 6-9 November 2014
}

It is now evident that interactions between tumor cells and host tissue stoma play a key role in tumor progression. Understanding the composition of the stromal cells in the tumor microenvironment immediately after tumor irradiation might be an important first step in understanding immunomodulation by radiation therapy. To explore this, we harvested tumor masses, draining lymph nodes (DLNs), spleens, and peripheral blood mononuclear cells (PBMCs) between 6h-96h after a single 15 Gy dose of focused irradiation of RM-9 mouse prostate tumor grafts growing in the hind leg of syngeneic C57BL/6 mice. Subpopulations of lymphocytes and granulocytes (CD4+, CD8+, CD4+CD25+, CD11c+, $\mathrm{CD} 11 \mathrm{~b}+\mathrm{Gr}-1+\mathrm{mid}$, and $\mathrm{CD} 1 \mathrm{~b}+\mathrm{Gr}-1+$ high cells) were analyzed by flow cytometry. We have previously reported that there is an infiltration of $\mathrm{CD} 11 \mathrm{~b}+\mathrm{Gr}-1$ +high neutrophils into the tumor that reached a peak within 24-48 h after tumor irradiation (Fig. 1A). To investigate the generality of this phenomenon, the lung cancer cell line LLC and the breast cancer cell line 4T1 was implanted in their respective syngeneic hosts; C57BL/6 and BALB/c mice. In both models neutrophilic infiltration was observed at 24-48h after tumor irradiation (Fig. 1B, C). To investigate the effect of neutrophils on tumor growth, we compared the tumor sizes in mice treated with the neutrophil-depleting anti-Ly-6G mAb to those of mice treated with an isotype-matched control antibody. The therapeutic effect of irradiation was significantly attenuated in all three tumor models when neutrophils were depleted (Fig. 2). To evaluate the impact of the neutrophilic infiltration on tumor-specific immune responses, we generated OVA gene-transfected RM-9 and RM-9-OVA-tumor-bearing mice for detecting

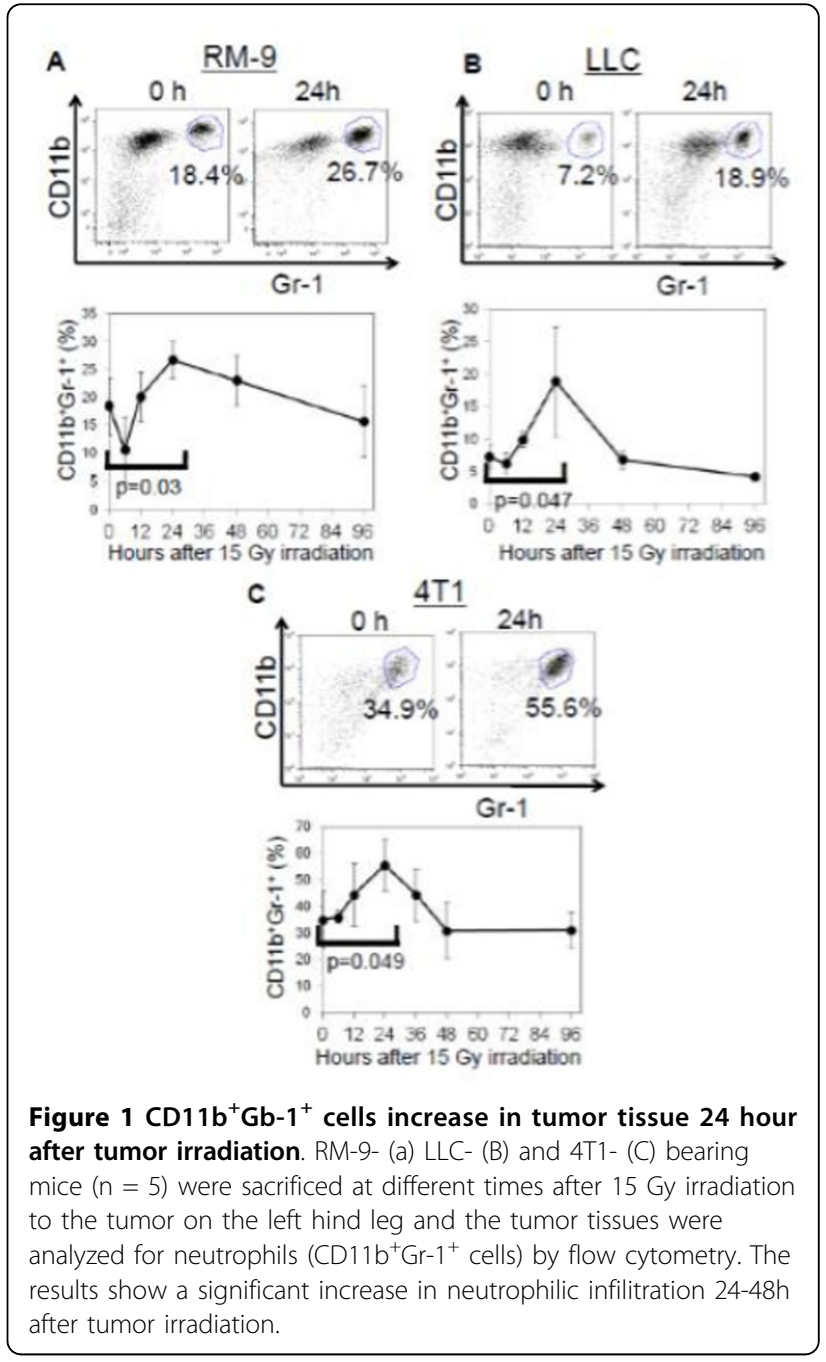

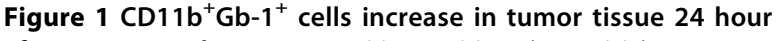
after tumor irradiation. RM-9- (a) LLC- (B) and 4T1- (C) bearing mice $(n=5)$ were sacrificed at different times after 15 Gy irradiation to the tumor on the left hind leg and the tumor tissues were results show a significant increase in neutrophilic infilitration 24-48h after tumor irradiation.

Univ. of Texas Southwestern Medical Center, Dallas, TX, USA 
OVA-specific CTL. Cohorts of RM-9-OVA-tumorbearing mice with and without neutrophil depletion by anti-Ly-6G mAb were irradiated focally with $15 \mathrm{~Gy}$. Nine days after irradiation, DLNs were harvested and started to culture under IL-2 and IL-12 with irradiated RM-9-OVA cells. Five days later, OVA-specific CTLs were quantified by flow cytometry after staining with

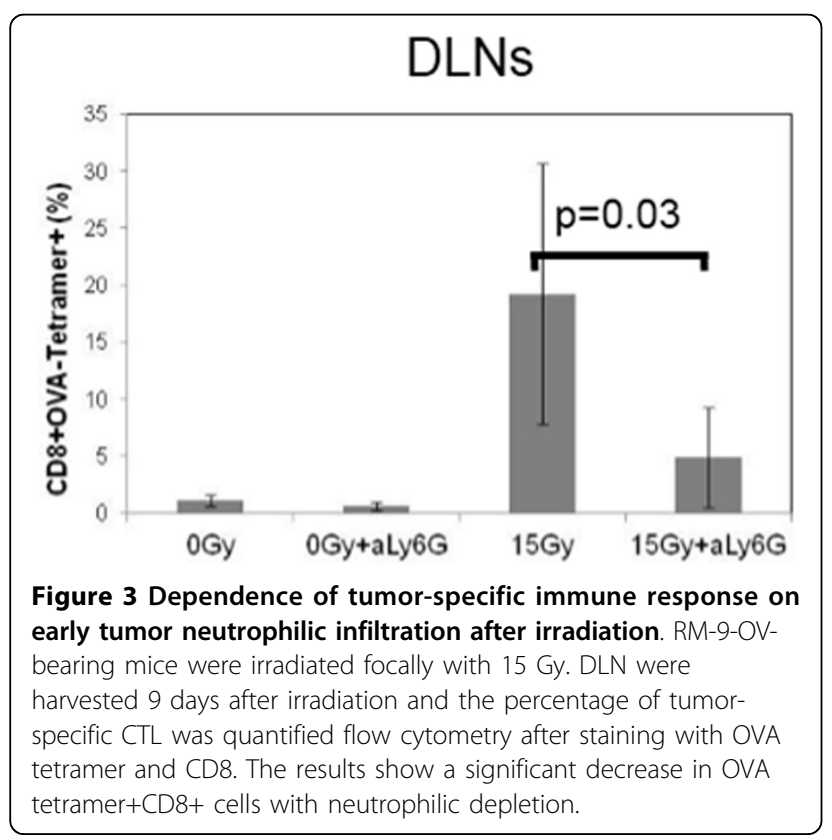

OVA-tetramer. The result (Fig. 3) shows an increased frequency of CD8+OVA-tetramer+ cells in irradiated tumorbearing mice and a decrease in CD8+OVA-tetramer+ cells in the neutrophil-depleted mice. Furthermore, this immune response correlates with the delay in tumor growth. Therefore, neutrophil infiltration may be an early but important step in the radio-immunomodulation of tumor that is important for the initiation adaptive tumorspecific immune responses. Current endeavors are focused on delineating the steps involved in the generation of tumor-specific immune response from radiation-induced neutrophilic infiltration.

Published: 6 November 2014

doi:10.1186/2051-1426-2-S3-P162

Cite this article as: Takeshima et al:: Anti-tumor characteristics of radiation-induced tumor-infiltrating neutrophils. Journal for ImmunoTherapy of Cancer 2014 2(Suppl 3):P162.

Submit your next manuscript to BioMed Central and take full advantage of:

- Convenient online submission

- Thorough peer review

- No space constraints or color figure charges

- Immediate publication on acceptance

- Inclusion in PubMed, CAS, Scopus and Google Scholar

- Research which is freely available for redistribution 